\title{
Efficacy and Safety of Aceclofenac Controlled Release in Patients with Knee Osteoarthritis: A 4-week, Multicenter, Randomized, Comparative Clinical Study
}

\author{
Young-Wan Moon, $\mathrm{MD}^{1}$, Seung-Baik Kang, $\mathrm{MD}^{2}$, Tae-Kyun Kim, $\mathrm{MD}^{3}$, and Myung-Chul Lee, $\mathrm{MD}^{4}$ \\ ${ }^{1}$ Department of Orthopedic Surgery, Samsung Medical Center, Sungkyunkwan University School of Medicine, Seoul; ${ }^{2}$ Department of Orthopedic Surgery, Seoul \\ National University Boramae Hospital, Seoul; ${ }^{3}$ Department of Orthopedic Surgery, Seoul National University Bundang Hospital, Seongnam; ${ }^{4}$ Department of Orthopedic \\ Surgery, Seoul National University Hospital, Seoul National University College of Medicine, Seoul, Korea
}

Purpose: To evaluate the analgesic effect, efficacy and safety of aceclofenac controlled release (CR) in patients with chronic knee osteoarthritis (OA). Materials and Methods: A total of 125 subjects with chronic knee OA were randomly divided into two groups: one group ( $\mathrm{n}=62$ ) was administered aceclofenac CR once daily and the other ( $\mathrm{n}=63$ ), aceclofenac immediate release (IR) twice a day for 4 weeks. A 100-mm visual analogue scale (VAS), Knee injury and Osteoarthritis Outcome Score (KOOS) and range of motoin (ROM) were evaluated as the outcome measures. To evaluate the safety of the drug, adverse events, vital signs, physical examination findings, clinical laboratory values and electrocardiographic findings were evaluated. Results: The VAS, KOOS and ROM were improved after 4 weeks of administration in both groups, but the differences between the two groups were not statistically significant. Significant differences between the two groups were not shown in the evaluation of the adverse events, vital sign, physical examination results, clinical laboratory values, and electrocardiography.

Conclusions: The aceclofenac CR and aceclofenac IR were equally effective in patients with chronic knee OA and the clinical trial results didn't show any significant difference in safety. The new aceclofenac CR formulation was found to be effective and safe with the practical advantage of once daily administration.

Keywords: Knee, Osteoarthritis, Aceclofenac, Controlled-release preparations

\section{Introduction}

Osteoarthritis (OA) of the knee is one of the most common conditions in the elderly, mostly associated with knee pain ${ }^{1,2)}$. Radiographic OA (ROA) is defined as a Kellgren and Lawrence grade of $\geq 2$, whereas symptomatic OA (SOA) refers to ROA accompanied by symptoms. Approximately $12 \%$ of the total US population was estimated to present with signs or symptoms of

Received August 6, 2013; Revised (1st) October 28, 2013;

(2nd) January 27, 2014; Accepted February 3, 2014

Correspondence to: Myung-Chul Lee, MD

Department of Orthopedic Surgery, Seoul National University Hospital, 101 Daehak-ro, Jongno-gu, Seoul 110-744, Korea

Tel: +82-2-2072-2368, Fax: +82-2-764-2718

E-mail: leemc@snu.ac.kr

This is an Open Access article distributed under the terms of the Creative Commons Attribution Non-Commercial License (http://creativecommons.org/licenses/by-nc/3.0/) which permits unrestricted non-commercial use, distribution, and reproduction in any medium, provided the original work is properly cited.
OA; in particular, ROA was diagnosed in $17 \%$ of the population aged 60 and over and in $70 \%$ of those $\geq 65$ years of age $e^{3,4)}$. Due to the growth of the senior population and the influence of the joint disease on the public heath, OA treatment has gained increasing attention.

The currently available OA treatment options include medication using non-steroidal anti-inflammatory drugs (NSAIDs) or selective Cyclooxygenase-type-2 (COX-2) inhibitors, physical therapy, intra-articular steroid injection, viscosupplementation, joint irrigation, arthroscopic knee surgery, and knee replacement surgery ${ }^{5,6)}$. NSAIDs have been widely used as the primary pain reliever in $\mathrm{SOA}^{7)}$, but treatment discontinuation may be required due to gastrointestinal side effects associated with COX-1 inhibi$\operatorname{tion}^{8,9)}$. On the other hand, aceclofenac has been established as a safe and effective medicine that demonstrates better safety and tolerance than other NSAIDs due to its superior selectivity for COX-2 inhibition for the past 20 years in south Korea ${ }^{10)}$.

However, the downside of aceclofenac lies in its inconvenient dosing regimen of twice daily. Cockburn et al. ${ }^{11)}$ demonstrated a www.jksrr.org 
relation between patients' medication compliance and the number of daily doses: the compliance with the medication that was only $38 \%$ with three-times-a-day dosing increased to $69 \%$ with twice-a-day dosing and then to $90 \%$ with once-a-day dosing. Thus, the study provides evidence that a reduced number of daily doses would result in higher compliance among patients, which would eventually improve treatment efficacy ${ }^{11)}$.

Compared to aceclofenac immediate release (IR) $100 \mathrm{mg}$ that requires twice-daily dosing, aceclofenac controlled release (CR) $200 \mathrm{mg}$ is formulated for once-daily dosing and composed of two layers, an IR layer and a CR layer.

The purpose of the current study was to evaluate non-inferiority of aceclofenac CR $200 \mathrm{mg}$ to aceclofenac IR $100 \mathrm{mg}$ with regard to it efficacy and safety in clinical setting.

\section{Materials and Methods}

\section{Study Subjects}

Of the patients between 40 and 70 years of age with chronic knee OA diagnosed with radiography and clinical examination, those presenting with knee OA symptoms lasting $\geq 3$ months and $>40 \mathrm{~mm}$ on a $100-\mathrm{mm}$ visual analogue scale (VAS) were included in this study. The followings were used as exclusion criteria: patients with a history of gastric ulcer, duodenal ulcer, gastrointestinal hemorrhage, or other abnormal bleeding; use of intra-articular or oral corticosteroids within 3 weeks prior to Visit 1 (randomization); intra-articular injection of hyaluronic acid within 1 week prior to Visit 1 or scheduled injection during clinical trial; patients with increased risk of asthma or asthma pa-

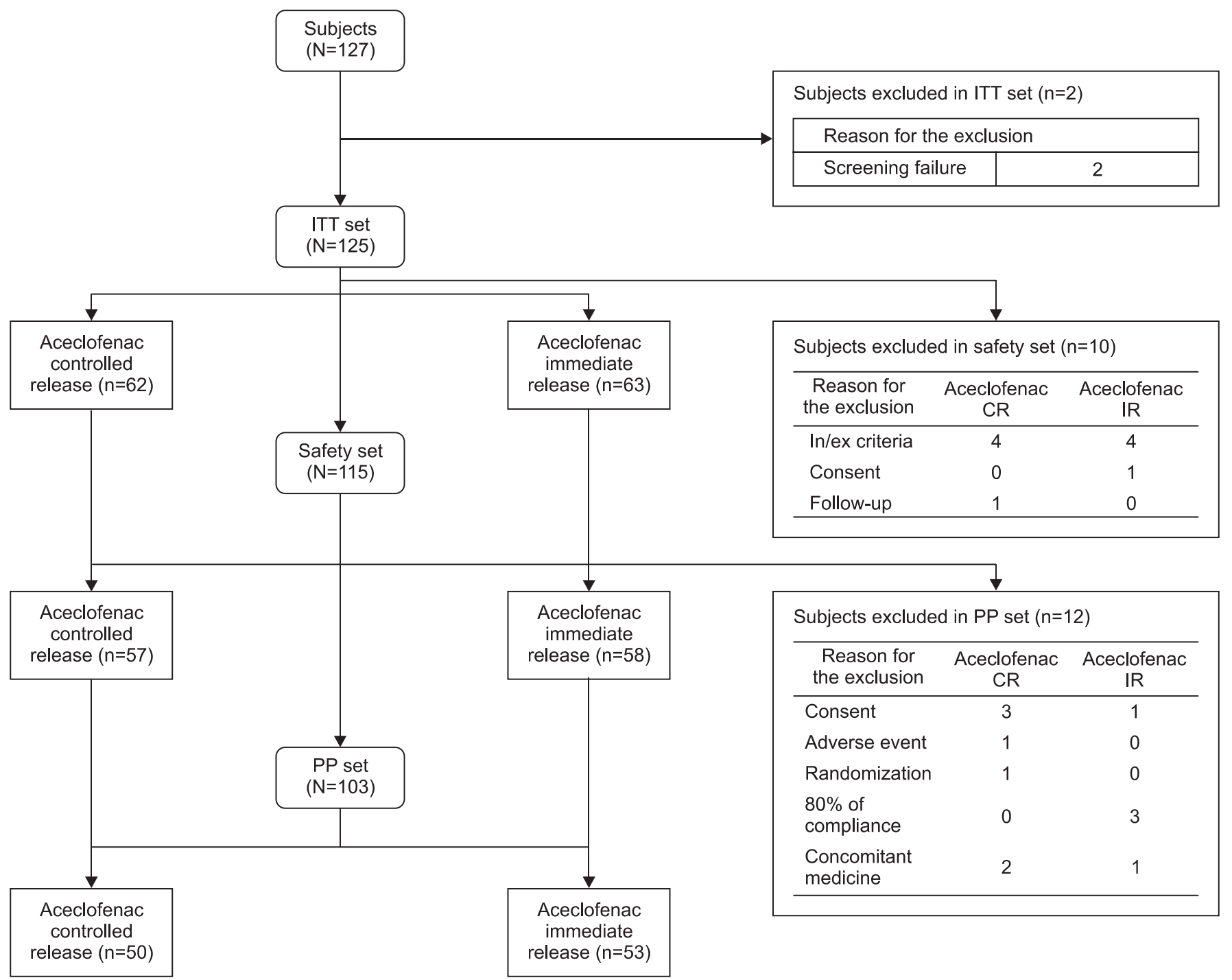

Fig. 1. Diposition of subjects. ITT: intention-to-treat, PP: per-protocol, CR: controlled release, IR: immediate release. 
tients at risk of developing hives or acute rhinitis due to aspirin or prostaglandin synthetase inhibitors; hypersensitivity to NSAIDs or other drugs of the same class (diclofenac) as the study drug; presence of severe cardiovascular, respiratory, renal, endocrine, hematological, gastrointestinal, or neuropsychiatric disorders or malignant tumors.

Of the total 127 patients who agreed to participate in the clinical trial, excluding 2 screening failures ( 1 due to hepatic dysfunction and 1 due to inclusion/exclusion criteria violation), 125 patients (experimental group, $\mathrm{N}=62$; control group, $\mathrm{N}=63$ )) were included

Table 1. Demographic/Baseline Data

\begin{tabular}{|c|c|c|c|}
\hline Variable & Aceclofenac CR $(\mathrm{n}=62)$ & Aceclofenac IR ( $n=63)$ & p-value \\
\hline Sex & & & $0.269^{\mathrm{a})}$ \\
\hline Male & $10(16.1)$ & $6(9.5)$ & \\
\hline Female & $52(83.9)$ & $57(90.5)$ & \\
\hline Age (yr) & $61.0 \pm 6.8$ & $61.6 \pm 6.1$ & $0.599^{\mathrm{b})}$ \\
\hline Weight (kg) & $64.9 \pm 9.2$ & $61.4 \pm 7.9$ & $0.144^{c)}$ \\
\hline Diagnosis-X-ray (Kellgren and Lawrence grade) & & & $0.367^{\mathrm{a})}$ \\
\hline Doubtful & $10(15.9)$ & $12(19.4)$ & \\
\hline Mild & $16(25.4)$ & $11(17.7)$ & \\
\hline Moderate & $24(38.1)$ & $19(30.7)$ & \\
\hline Severe & $13(20.6)$ & $20(32.3)$ & \\
\hline Chronic knee OA expected duration (mo) & $58.7 \pm 56.5$ & $54.9 \pm 46.8$ & $0.589^{c)}$ \\
\hline \multicolumn{4}{|l|}{ Other history } \\
\hline Yes & $42(67.7)$ & $35(55.6)$ & \\
\hline No & $20(32.3)$ & $28(44.4)$ & \\
\hline Vascular disorders & $26(41.9)$ & $20(31.8)$ & \\
\hline Metabolism and nutrition disorders & $14(22.6)$ & $14(22.2)$ & \\
\hline Musculoskeletal and connective tissue disorders & $11(17.7)$ & $9(14.3)$ & \\
\hline Infections and infestations & $5(8.1)$ & - & \\
\hline Nervous system disorders & $4(6.5)$ & $1(1.6)$ & \\
\hline Gastrointestinal disorders & $1(1.6)$ & - & \\
\hline Hepatobiliary disorders & $2(3.2)$ & $1(1.6)$ & \\
\hline Neoplasms benign, malignant and unspecified (incl cysts and polyps) & - & $2(3.2)$ & \\
\hline Surgical and medical procedures & $1(1.6)$ & $1(1.6)$ & \\
\hline Endocrine disorders & $2(3.2)$ & - & \\
\hline Injury, poisoning and procedural complications & $1(1.6)$ & $1(1.6)$ & \\
\hline Ear and labyrinth disorders & $1(1.6)$ & - & \\
\hline Eye disorders & $1(1.6)$ & - & \\
\hline Respiratory, thoracic and mediastinal disorders & - & $1(1.6)$ & \\
\hline Reproductive system and breast disorders & $1(1.6)$ & - & \\
\hline Skin and subcutaneous tissue disorders & $1(1.6)$ & - & \\
\hline Treatment history & & & $0.125^{\mathrm{a})}$ \\
\hline Yes & $38(61.3)$ & $30(47.6)$ & \\
\hline No & $24(38.7)$ & $33(52.4)$ & \\
\hline
\end{tabular}

Values are presented as number (\%) or mean \pm standard deviation.

CR: controlled release, IR: immediate release.

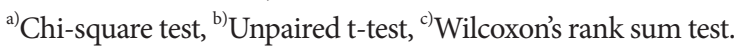


in the intention-to-treat (ITT) analysis. Of these, excluding 22 patients due to low compliance, use of prohibited medications, or inclusion/exclusion criteria violation, 103 patients (experimental group, $\mathrm{N}=50$; control group, $\mathrm{N}=53$ ) were evaluated in the perprotocol (PP) analysis,.

In the safety evaluation, 115 of the 125 patients who were eligible for the ITT analysis were included (experimental group, $\mathrm{N}=57$; control group, $\mathrm{N}=58$ ), except for 8 patients who violated the inclusion/exclusion criteria and 2 patients who were not available for the safety assessment after drug administration (Fig. 1, Table 1). There were no notable intergroup differences with regard to demographics.

The safety evaluation was based on the incidence of adverse events, clinical laboratory test results, physical examination findings, vital signs, and electrocardiographic findings. Patients with missing data were excluded only from the respective analyses on the missing variables.

\section{Clinical Trial}

The phase 4 multicenter, open-label, randomized, non-inferiority, comparative clinical trial was conducted at Seoul National University Hospital, Samsung Medical Center, Seoul National University Borame Medical Center, Seoul National University Bundang Hospital between January 24, 2011 and March 30, 2012. Pareek et al. ${ }^{12)}$ reported that the mean VAS change between the baseline and at 4 weeks after treatment was $6.9 \mathrm{~mm}$ greater in the aceclofenac group (left knee, $-15.7 \mathrm{~mm}$; right knee, $-15.7 \mathrm{~mm}$ ) than in the diclofenac group (left knee, $-8.8 \mathrm{~mm}$; right knee, $-8.8 \mathrm{~mm}^{12}$ ). Based on the study, the mean VAS change at 4 weeks after treatment for knee OA was assumed to be $-15.7 \mathrm{~mm}$, the actual mean VAS change in the aceclofenac group of the above-mentioned study, with a standard deviation (SD) of $\pm 15.9 \mathrm{~mm}$, the greatest $\mathrm{SD}$ described in the study. When the mean intergroup difference in VAS at 4 weeks after treatment as assumed to be $-6.1 \mathrm{~mm}$, the mean VAS change in the CR group was calculated as $-21.8 \mathrm{~mm}$ and the non-inferiority limit was defined as $-15 \mathrm{~mm}$. The sample size for each group required for a confidence interval of $95 \%$ and power of $80 \%$ was calculated using the following formula:

$$
\mathrm{n}=\frac{2\left(Z_{\alpha}+Z_{\beta}\right)^{2} \sigma^{2}}{(\varepsilon-\delta)^{2}}=40
$$

Taking into account potential dropouts from the trial, the number of patients required was determined as $\geq 120$.

If the patient diagnosed with chronic OA agreed to participate in the clinical trial, after one week of wash-out period depending

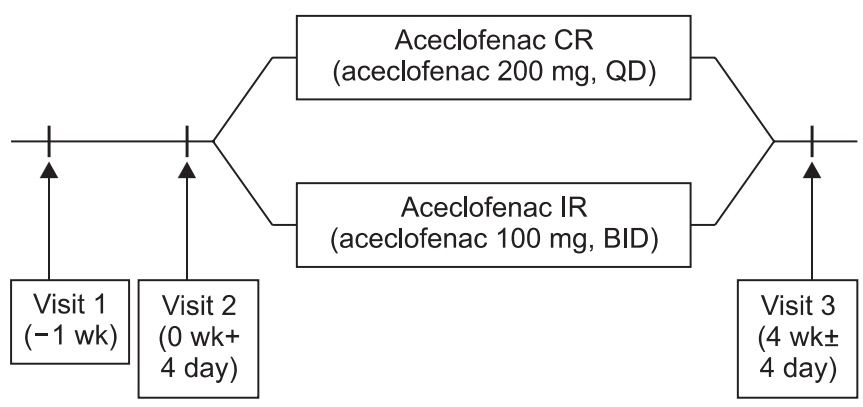

Fig. 2. Schedule for clinical practice. CR: controlled release, QD: once a day, IR: immediate release, BID: twice a day.

on the medication prior to trial, the eligibility of the patient for the study was determined based on the inclusion/exclusion criteria. Then, the patient was assigned with 1:1 randomization into the CR group or the IR group. The patient allocation was done independently at each participating institution using a computergenerated randomization table. To ensure balanced randomization between groups, a randomized block design with block sizes 4 and 6 and a ratio of 1:1 was used.

The randomly assigned subjects were treated with either aceclofenac CR $200 \mathrm{mg}$ once daily or aceclofenac IR $100 \mathrm{mg}$ twice daily for 4 weeks. The efficacy and safety of the treatment were tested at each clinic upon the end of the treatment.

The experimental group received oral administration of an aceclofenac CR tablet 200 mg (Clanza CR; Korea United Pharm Inc., Seoul, Korea) once daily, whereas the control group, an aceclofenac IR tablet 100 mg (Airtal; Dae-Woong Pharm Co Ltd., Seoul, Korea) twice daily (Fig. 2).

The primary variable used for the evaluation of efficacy was the mean change in 100-mm VAS between baseline and at 4 weeks after treatment. The secondary variables were the Knee injury and Osteoarthritis Outcome Score (KOOS) function (pain, daily living, sports and recreational activities, and quality of life) and range of motion (ROM, flexion contracture-further flexion). For the evaluation of safety, development of adverse events during the clinical trial, abnormal findings in physical examination, and changes in clinical laboratory test results were assessed.

\section{Evaluation and Statistical Analysis}

The efficacy evaluation was primarily based on the ITT analysis and secondarily on the PP analysis.

Changes in the 100-mm VAS for pain, the primary variable for the efficacy evaluation, between the baseline and at 4 weeks after treatment were compared. The pre- and post-administration differences were compared in each group. Regarding the intergroup 
comparison, non-inferiority of the experimental group was evaluated by investigating whether the lower limit of a one-sided $95 \%$ confidence interval was above the equivalence margin of -15 $\mathrm{mm}$. The signed rank test was used to compare the pre- and postadministration differences in each group. As for the intergroup comparison, the Wilcoxon's rank sum test was performed and a covariance analysis was carried out with the institutions taken as the covariate.

The secondary efficacy evaluation variables included KOOSpain, KOOS-daily Living, KOOS-sports and recreational activities, and KOOS-quality of life. The KOOS-pain, designed to assess knee joint symptoms, was calculated as the sum of scores on a 9-item questionnaire, and the pre- and post-administration differences were compared. A higher score was considered to indicate less pain. The KOOS-daily Living was assessed as the sum of scores on a 17-item questionnaire, and the pre- and postadministration differences were compared. A higher score was interpreted to represent less difficulty in performing daily living activities. Regarding the assessment of KOOS-sports and recreational activities, the pre- and post-administration differences in the sum of scores on a 5-item questionnaire were compared. A higher score was regarded as less difficulty with sports and recreational activities. The KOOS-quality of life was measured as the sum of scores on a 5-item questionnaire, and the pre- and postadministration differences were compared. A higher score was considered as an indication of higher quality of life. Intergroup comparisons regarding the four subscales of the KOOS were performed using the Wilcoxon's rank sum test.

For the assessment of ROM of the knee, the pre- and post-administration differences in the active range of flexion measured with the patient in a sitting position were compared, and intergroup comparison was performed using either the Wilcoxon's rank sum test or an unpaired t-test.

On the safety evaluation, intergroup differences in adverse events, clinical laboratory test results, physical examination find- ings, vital signs, and electrocardiographic results were analyzed using either Chi-square test or Fisher's exact test.

\section{Results}

\section{Primary Variable for the Efficacy Evaluation: 100-mm Visual Analogue Scale}

In the total 125 patients included in the ITT analysis, the 100mm VAS decreased after administration compared to pre-administration. The VAS decreased from $66.5 \pm 16.4 \mathrm{~mm}$ before administration (visit 2) to $43.2 \pm 20.7 \mathrm{~mm}$ at 4 weeks after administration (visit 3) by $24.0 \pm 19.2 \mathrm{~mm}$ in the experimental group $(\mathrm{p}<0.001)$. In the control group, the value decreased form $62.5 \pm 13.9 \mathrm{~mm}$ before administration (visit 2) to $43.3 \pm 20.1 \mathrm{~mm}$ at 4 weeks after administration (visit 3), by $19.3 \pm 18.7 \mathrm{~mm}(\mathrm{p}<0.001)$. The intergroup difference in the 100-mm VAS decrease between the preand post-administration was $4.8 \pm 18.9 \mathrm{~mm}$. The lower limit of the one-sided $95 \%$ confidence interval $(-1.17, \infty)$ was above the equivalence margin of $-15 \mathrm{~mm}$, thus the non-inferiority of the experimental group to the control group was confirmed.

The Wilcoxon's rank sum test showed there was no significant difference in the pre- and post-administration VAS score changes between the groups $(\mathrm{p}=0.106)$. In the covariance analysis, the intergroup was not statistically significant when institutional difference was adjusted as a covariate $(\mathrm{p}=0.177)$ (Table 2$)$.

Among the total 103 patients involved in the PP analysis, the 100-mm VAS decreased between pre- and post-administration. The VAS decreased from $66.9 \pm 15.6 \mathrm{~mm}$ before administration (visit 2) to $43.2 \pm 19.1 \mathrm{~mm}$ at 4 weeks after administration (visit 3) by $23.7 \pm 19.5 \mathrm{~mm}$ in the experimental group ( $<<0.001)$. In the control group, the decrease was from $63.2 \pm 14.1 \mathrm{~mm}$ before administration (visit 2) to $44.2 \pm 20.2 \mathrm{~mm}$ at 4 weeks after administration (visit 3 ) by $19.0 \pm 18.0 \mathrm{~mm}(\mathrm{p}<0.001)$. The intergroup difference in the 100-mm VAS decrease between pre- and postadministration was $4.7 \pm 18.7 \mathrm{~mm}$. The lower limit of the one-sid-

Table 2. 100-mm VAS-ITT Set

\begin{tabular}{|c|c|c|c|c|c|}
\hline \multirow{2}{*}{ 100-mm VAS } & \multicolumn{2}{|c|}{ Aceclofenac CR } & \multicolumn{2}{|c|}{ Aceclofenac IR } & \multirow{2}{*}{$\mathrm{p}$-value } \\
\hline & Mean \pm SD & No. & Mean \pm SD & No. & \\
\hline Baseline $^{\text {a) }}$ & $66.5 \pm 16.4$ & 62 & $62.5 \pm 13.9$ & 63 & $0.206^{\mathrm{b})}$ \\
\hline After $4 w^{a)}$ & $43.2 \pm 20.7$ & 55 & $43.3 \pm 20.1$ & 57 & - \\
\hline Changes (0, 4 wk) & $-24.0 \pm 19.2$ & 55 & $-19.3 \pm 18.7$ & 57 & $0.106^{b)}$ \\
\hline Adjusted changes $^{\mathrm{c})}(0,4 \mathrm{wk})$ & $-24.0 \pm 2.5$ & 55 & $-19.2 \pm 2.5$ & 57 & $0.177^{\mathrm{d})}$ \\
\hline
\end{tabular}

VAS: visual analogue scale, ITT: intention-to-treat, CR: controlled release, IR: immediate release, SD: standard deviation.

${ }^{a)}$ Signed rank test, ${ }^{\text {b) }}$ Wilcoxon's rank sum test, ${ }^{\text {c) }}$ Changes adjusted by using institutional difference as a covariate (least square mean \pm standard error), ${ }^{\text {d) }}$ Analysis of covariance. 
Table 3. KOOS and ROM-ITT Set

\begin{tabular}{|c|c|c|c|c|c|}
\hline \multirow{2}{*}{ Variable } & \multicolumn{2}{|c|}{ Aceclofenac CR } & \multicolumn{2}{|c|}{ Aceclofenac IR } & \multirow{2}{*}{$\mathrm{p}$-value } \\
\hline & Mean \pm SD & No. & Mean \pm SD & No. & \\
\hline \multicolumn{6}{|l|}{ Changes in $\operatorname{KOOS}(0,4$ wk) } \\
\hline Pain & $3.6 \pm 4.8$ & 55 & $2.9 \pm 4.9$ & 58 & $0.367^{\mathrm{a})}$ \\
\hline Daily living & $6.9 \pm 10.5$ & 55 & $4.6 \pm 8.7$ & 58 & $0.138^{\mathrm{a})}$ \\
\hline Sport and recreational activities & $2.3 \pm 3.5$ & 55 & $2.2 \pm 4.1$ & 58 & $0.870^{\mathrm{b})}$ \\
\hline Quality of life & $1.3 \pm 2.5$ & 55 & $1.5 \pm 2.2$ & 58 & $0.787^{\mathrm{a})}$ \\
\hline \multicolumn{6}{|l|}{ Changes in ROM (0, 4 wk) } \\
\hline Flexion contracture & $-0.6 \pm 5.4$ & 55 & $-1.0 \pm 3.1$ & 57 & $0.289^{\mathrm{a})}$ \\
\hline Further flexion & $2.0 \pm 5.2$ & 55 & $1.8 \pm 6.7$ & 57 & $0.689^{\mathrm{a})}$ \\
\hline Range (FF-FC) & $2.6 \pm 8.0$ & 55 & $2.8 \pm 7.3$ & 57 & $0.965^{\mathrm{a})}$ \\
\hline
\end{tabular}

Values are presented as mean \pm standard deviation.

KOOS: knee injury and osteoarthritis outcome score, ROM: range of motion, ITT: intention-to-treat, CR: controlled release, IR: immediate release. FF: further flexion, FC: flexion contracture.

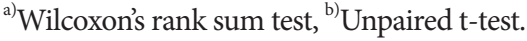

ed $95 \%$ confidence interval $(-1.43, \infty)$ was above the equivalence margin of $-15 \mathrm{~mm}$, thus non-inferiority of the experimental group to the control group was confirmed.

The Wilcoxon's rank sum test showed there was no significant different between the groups in the pre- and post-administration VAS changes $(\mathrm{p}=0.130)$. In the covariate analysis, the intergroup difference in the VAS change was not statistically significant when institutional difference was adjusted as a covariate $(\mathrm{p}=0.169)$.

\section{Secondary Variable for Efficacy Evaluation: Knee Injury and Osteoarthritis Outcome Score}

The knee joint condition was assessed using the four KOOS subscales, including KOOS-pain, KOOS-daily living, KOOSsports and recreational activities, and KOOS-quality of life. The pre- and post-administration change in the KOOS-pain score was $3.9 \pm 4.8$ points in the experimental group and $2.9 \pm 4.9$ points in the control group. The KOOS-daily living score change between pre- and post-administration was $6.9 \pm 10.5$ points in the experimental group and $4.6 \pm 8.7$ points in the control group. The pre- and post-administration KOOS-sports and recreational activities scores were different by $2.3 \pm 3.5$ points in the experimental group and $2.2 \pm 4.1$ points in the control group.

The pre- and post-administration difference in the KOOSquality of life score was $1.3 \pm 2.5$ points in the experimental group and $1.5 \pm 2.2$ points in the control group.

The experimental group exhibited greater improvement in the KOOS-pain, KOOS-daily living, and KOOS-sports and recreational Activities, whereas the control group demonstrated higher increase in the KOOS-quality of life; however, the intergroup dif-
Table 4. Number of Adverse Events and Adverse Drug Reactions-Safety Set

\begin{tabular}{lccc}
\hline \multicolumn{1}{c}{ Variable } & $\begin{array}{c}\text { Aceclofenac } \\
\text { CR }(\mathrm{n}=57)\end{array}$ & $\begin{array}{c}\text { Aceclofenac } \\
\text { IR (n=58) }\end{array}$ & p-value ${ }^{\text {a) }}$ \\
\hline No. of adverse events & 15 & 11 & 0.129 \\
No. of adverse drug reactions & 14 & 11 & 0.195 \\
\hline
\end{tabular}

CR: controlled release, IR: immediate release.

${ }^{\text {a) }}$ Chi-square test.

ferences were not statistically significant with regard to any of the four KOOS subscales. ( $\mathrm{p}=0.367, \mathrm{p}=0.138, \mathrm{p}=0.870$, and $\mathrm{p}=0.787$, respectively) (Table 3$)$.

\section{Secondary Variable for Efficacy Evaluation: Range of Motion}

The ROM (further flexion-flexion contracture) was improved from $131.2^{\circ} \pm 11.0^{\circ}$ before administration (visit 2) to $134.4^{\circ} \pm 9.3^{\circ}$ at 4 weeks after administration (visit 3 ) by $2.6^{\circ} \pm 8.0^{\circ}(\mathrm{p}=0.025)$ in the experimental group. During the same period, the ROM in the control group was improved from $132.2^{\circ} \pm 10.6^{\circ}$ to $135.4^{\circ} \pm 10.0^{\circ}$ by $2.8^{\circ} \pm 7.3^{\circ}(p=0.002)$. However, the intergroup difference in the ROM $\left(-0.1^{\circ} \pm 7.6^{\circ}\right.$; ROM of the experimental group-ROM of the control group) was not statistically significant $(\mathrm{p}=0.965)$ (Table 3 ).

\section{Safety Evaluation}

A total of 26 adverse events developed in 20 of the 115 patients (17.4\%) during the clinical trial: 15 cases in 13 of the 57 experimental group patients (22.8\%) and 11 cases in 7 of the 58 control group patients $(12.1 \%)(\mathrm{p}=0.129)$. Fourteen adverse drug 
reactions were found in 12 patients (21.1\%) in the experimental group and 11 cases were observed in 7 patients (12.1\%) in the control group ( $\mathrm{p}=0.195)$. No significant intergroup differences were found in the numbers of adverse events and adverse drug reactions (Table 4). The 15 adverse events in the experimental group included indigestion (10), abdominal pain (1), facial swelling (1), peripheral edema (1), palpitation (1), and inappetence (1), and the peripheral edema case was not counted as an adverse drug reaction. The 11 adverse events in the control group were indigestion (4), facial swelling (2), chest discomfort (1), swelling (1), increase of gamma-glutamyltransferase (1), increase of alanine aminotransferase (1), and increase of aspartate aminotransferase (1). All of these adverse drug reactions were predictable, not unexpected, based on the previous literature, and serious adverse drug reactions were not found during the clinical trial.

On the vital sign (blood pressure and pulse) examination, the systolic and diastolic pressures were higher after administration in both groups. The post-administration heart rate was increased in the experimental group and decreased in the control group, but the values were within normal range in both groups, showing no insignificant difference between groups.

The physical examination revealed abnormal findings before administration in 4 patients in the experimental group (eye in 1 , skin in 2, and musculoskeletal system in 1 patient) and in 3 patients in the control group (musculoskeletal system in 3 patients). After administration, 1 in 4 of the former group became normal and the abnormal findings in the 3 remaining patients were not considered clinically significant. All 3 patients in the latter group became normal after administration.

Pre- and post-administration clinical laboratory tests, including blood tests, blood chemistry tests, and urine tests did not reveal notable changes in both groups.

Electrocardiography showed normal findings in 41 patients (73.2\%) and clinically insignificant level of abnormality in 15 patients (26.8\%) in the experimental group before administration. After administration, 35 patients (64.8\%) were normal and 19 patients (35.2\%) had clinically insignificant abnormality. In the control group, 32 patients (57.1\%) were normal and 24 patients (42.9\%) had clinically insignificant abnormality before administration. After administration, 32 patients (57.1\%) were normal and 24 patients (42.9\%) had clinically insignificant abnormality.

\section{Discussion}

Aceclofenac is a phenylacetic acid-derived NSAID that is used not only for chronic joint conditions, such as OA, rheumatoid ar- thritis, and ankylosing spondylitis but also for relief of acute pain, especially following surgery ${ }^{8,13}$.

Compared to other anti-inflammatory drugs, such as diclofenac and naproxen, it exhibits excellent therapeutic effects by easily penetrating into inflammatory tissue, such as a joint, and accordingly effectively suppressing prostaglandin production. It has superior selectivity for COX-2 inhibition and thus does not disrupt generation of normal prostaglandin in the stomach mucosa, resulting in reduced gastrointestinal problems and adverse reactions and a high tolerance. Therefore, aceclofenac has been considered suitable for long-term use ${ }^{8,9)}$. In addition, it inhibits generation of interleukin-1 that destroys cartilage in a joint and promotes generation of glycosaminoglycan, a articular cartilage component, contributing to prevention of deterioration of rheumatoid arthritis or OA. In particular, the drug has been known to reduce pain and symptomatic severity and improve functional capacity of an injured joint, especially in cases of knee $\mathrm{OA}^{10)}$.

In a clinical trial that compares the efficacy of aceclofenac with piroxicam among 240 patients with OA of the knee, Perez et al. $^{14)}$ showed that although there were no significant differences between the two drugs with regard to the VAS, osteoarthritis severity index, severity index of gonarthritis, and ROM after two months of administration, aceclofenac facilitated more rapid improvement in ROM. According a critical trial by Ward et al. ${ }^{15)}$ on comparison with diclofenac in 397 patients and another clinical trial by Kornasoff et al. ${ }^{16)}$ on comparison with naproxen in 374 patients, aceclofenac did not demonstrate significant difference with the other two drugs in terms of efficacy after 3 months of treatment; however, tolerability of aceclofenac was found better than the other two drugs because fewer patients presented with gastrointestinal adverse events after treatment with aceclofenac. This can be attributed to the fact that aceclofenac is less effective in COX-1 inhibition and more potent in COX-2 inhibition than naproxen ${ }^{17)}$. Aceclofenac is either metabolized to 4 '-hydroxyaceclofenac by CYP2C9 and then converted into 4'-hydroxy-diclofenac by hydrolysis or hydrolyzed to diclofenac and then converted into 4'-hydroxy-diclofenac by CYP2C $9^{18,19)}$. Henrotin et al. ${ }^{20)}$ reported that aceclofenac and 4'-hydroxyaceclofenac inhibits COX2 only, which may explain why aceclofenac demonstrates better tolerance than naproxen.

Aceclofenac is a pro-drug that is activated by metabolites and has a short biological half-life of 2-4 hours. Thus, once or twice daily administration is necessary to maintain the efficacy of aceclofenac and major metabolites, 4'-hydroxy-aceclofenac, 4'-hydroxydiclofenac, and diclofenac ${ }^{21,22)}$.

In contrast, Celecoxib and Meloxicam are NSAIDs that have 
a long elimination half-life of 11 hours $^{23,24)}$ and 20 hours ${ }^{25)}$, respectively. Thus, once daily dosing is sufficient to maintain their plasma concentration and patient compliance with the drugs is high. Aceclofenac CR was designed to be composed of two layers, an IR and a CR, to maintain its plasma concentration with once-daily administration. In addition, considering that it has a shorter maximum drug concentration time than Celecoxib and Meloxicam and a longer elimination half-life than aceclofenac IR, it would offer considerable advantages in the management of acute/chronic pain ${ }^{21-25)}$. In a clinical trial for pharmacokinetic comparison of CR formulation and aceclofenac IR formulation in healthy Korean subjects, the elimination half-life of the CR formulation was significantly longer than that of the IR formulation (5 hours vs. 2 hours) ${ }^{21)}$.

In our clinical trial, the non-inferiority of the experimental group was confirmed with 100-mm VAS, the primary variable for efficacy evaluation. The VAS was decreased by $4.8 \pm 18.9 \mathrm{~mm}$ more in the experimental group than in the control group, indicating the $\mathrm{CR}$ formulation has a more effective pain relieving effect, although the difference was not statistically significant $(\mathrm{p}=0.106)$. The two secondary variables used for efficacy evaluation were the KOOS and ROM. The KOOS was employed instead of Western Ontario and McMaster Universities (WOMAC) OA index because it is basically comprised of the same subscales of the WOMAC ${ }^{26-29)}$. There was no statistically significant difference in the KOOS and ROM between the groups.

There was no notable intergroup difference in the incidence of adverse events and adverse drug reactions $(\mathrm{p}=0.195)$. With regard to vital signs (blood pressure and pulse), there were no significant changes in the systolic/diastolic pressures and heart rates in both groups. The physical examination and clinical laboratory tests (blood tests, blood chemistry tests, and urine tests) did not reveal any abnormality.

These results of the 4 weeks of clinical trial involving patients with chronic knee OA confirm that the safety of once daily use of aceclofenac CR $200 \mathrm{mg}$ formulation are comparable to that of twice daily use of aceclofenac IR $100 \mathrm{mg}$. Thus, it is our understanding that the aceclofenac CR would be as safe as the aceclofenac IR among Knee OA patients whose long-term use of a painkiller is generally unavoidable.

However, we think that more than 4 weeks of long-term safety and efficacy evaluations should be conducted to generalize the results obtained from our clinical trial. It is necessary to confirm whether the equivalent level of safety and efficacy can be established after more than 4 weeks of administration period. One of the limitations of this study is that it was not conducted in a double-blinded manner due to the dosage difference between the two drugs. The safety and efficacy of the two aceclofenac fomulations were compared in patients with chronic knee OA only in our study. We believe comparisons between aceclofenac and other NSAIDs in patients with other OA, rheumatoid arthritis, and ankylosing spondylitis should be conducted in further studies.

\section{Conclusions}

This study showed that aceclofenac CR $200 \mathrm{mg}$ formulation was equivalent to aceclofenac IR $100 \mathrm{mg}$ formulation with respect to pain relief and safety among patients with chronic OA of the knee. In addition, the once daily dosage of aceclofenac CR contributed to enhanced patient compliance. Therefore, we think that aceclofenac CR $200 \mathrm{mg}$ is a safe and effective medicine that would provide effective pain management and improved quality of life in patients with chronic OA of the knee.

\section{Conflict of Interest}

No potential conflict of interest relevant to this article was reported.

\section{Acknowledgments}

This study was supported by a grant from Korea United Pharm Inc. between 2011 and 2012 .

\section{References}

1. Calis M, Demir H, Ulker S, Kirnap M, Duygulu F, Calis HT. Is intraarticular sodium hyaluronate injection an alternative treatment in patients with adhesive capsulitis? Rheumatol Int. 2006;26:536-40.

2. Rovetta G, Monteforte P. Intraarticular injection of sodium hyaluronate plus steroid versus steroid in adhesive capsulitis of the shoulder. Int J Tissue React. 1998;20:125-30.

3. Lawrence RC, Helmick CG, Arnett FC, Deyo RA, Felson DT, Giannini EH, Heyse SP, Hirsch R, Hochberg MC, Hunder GG, Liang MH, Pillemer SR, Steen VD, Wolfe F. Estimates of the prevalence of arthritis and selected musculoskeletal disorders in the United States. Arthritis Rheum. 1998;41:77899.

4. Kelley WN, Harris ED, Ruddy S, Sledge CB, eds. Textbook of rheumatology. 5th ed. Philadelphia: W.B. Saunders; 1997. 
5. Vad VB, Bhat AL, Sculco TP, Wickiewicz TL. Management of knee osteoarthritis: knee lavage combined with hylan versus hylan alone. Arch Phys Med Rehabil. 2003;84:634-7.

6. Hochberg MC, Altman RD, Brandt KD, Clark BM, Dieppe PA, Griffin MR, Moskowitz RW, Schnitzer TJ. Guidelines for the medical management of osteoarthritis. Part II. Osteoarthritis of the knee. American College of Rheumatology. Arthritis Rheum. 1995;38:1541-6.

7. Tamai K, Mashitori H, Ohno W, Hamada J, Sakai H, Saotome K. Synovial response to intraarticular injections of hyaluronate in frozen shoulder: a quantitative assessment with dynamic magnetic resonance imaging. J Orthop Sci. 2004;9:230-4.

8. Gowda KV, Rajan DS, Mandal U, Selvan PS, Sam Solomon WD, Bose A, Sarkar AK, Pal TK, Chattaraj TK. Evaluation of bioequivalence of two formulations containing 100 milligrams of aceclofenac. Drug Dev Ind Pharm. 2006;32:121925.

9. Hinz B, Auge D, Rau T, Rietbrock S, Brune K, Werner U. Simultaneous determination of aceclofenac and three of its metabolites in human plasma by high-performance liquid chromatography. Biomed Chromatogr. 2003;17:268-75.

10. Dooley M, Spencer CM, Dunn CJ. Aceclofenac: a reappraisal of its use in the management of pain and rheumatic disease. Drugs. 2001;61:1351-78.

11. Cockburn J, Reid AL, Bowman JA, Sanson-Fisher RW. Effects of intervention on antibiotic compliance in patients in general practice. Med J Aust. 1987;147:324-8.

12. Pareek A, Chandanwale AS, Oak J, Jain UK, Kapoor S. Efficacy and safety of aceclofenac in the treatment of osteoarthritis: a randomized double-blind comparative clinical trial versus diclofenac: an Indian experience. Curr Med Res Opin. 2006;22:977-88.

13. Movilia PG. Evaluation of the analgesic activity and tolerability of aceclofenac in the treatment of post-episiotomy pain. Drugs Exp Clin Res. 1989;15:47-51.

14. Perez Busquier M, Calero E, Rodriguez M, Castellon Arce P, Bermudez A, Linares LF, Mesa J, Ffernandez Crisostomos C, Garcia C, Garcia Lopez A, Valenzuela A, Povedano A, Garcia Perez S, Lopez MA, Caliz R, Garcia Villalba F, Cano M, Gines Martinez F, Gonzalez J, Caracuel MA, Roldan R, Guzman Ubeda M, Gonzalez A, Marenco de la Fuente IL, Alepuz Pou M, et al. Comparison of aceclofenac with piroxicam in the treatment of osteoarthritis. Clin Rheumatol. 1997;16:154-9.

15. Ward DE, Veys EM, Bowdler JM, Roma J. Comparison of aceclofenac with diclofenac in the treatment of osteoarthritis. Clin Rheumatol. 1995;14:656-62.

16. Kornasoff D, Frerick H, Bowdler J, Montull E. Aceclofenac is a well-tolerated alternative to naproxen in the treatment of osteoarthritis. Clin Rheumatol. 1997;16:32-8.

17. Masso Gonzalez EL, Patrignani P, Tacconelli S, García Rodriguez LA. Variability among nonsteroidal antiinflammatory drugs in risk of upper gastrointestinal bleeding. Arthritis Rheum. 2010;62:1592-601.

18. Bort R, Ponsoda X, Carrasco E, Gomez-Lechon MJ, Castell JV. Metabolism of aceclofenac in humans. Drug Metab Dispos. 1996;24:834-41.

19. Bort R, Ponsoda X, Carrasco E, Gomez-Lechon MJ, Castell JV. Comparative metabolism of the nonsteroidal antiinflammatory drug, aceclofenac, in the rat, monkey, and human. Drug Metab Dispos. 1996;24:969-75.

20. Henrotin Y, de Leval X, Mathy-Hartet M, Mouithys-Mickalad A, Deby-Dupont G, Dogne JM, Delarge J, Reginster JY. In vitro effects of aceclofenac and its metabolites on the production by chondrocytes of inflammatory mediators. Inflamm Res. 2001;50:391-9.

21. Bae SK, Kim SH, Lee HW, Seong SJ, Shin SY, Lee SH, Lim MS, Yoon YR, Lee HJ. Pharmacokinetics of a new once-daily controlled-release formulation of aceclofenac in Korean healthy subjects compared with immediate-release aceclofenac and the effect of food: a randomized, open-label, threeperiod, crossover, single-centre study. Clin Drug Investig. 2012;32:111-9.

22. Najib N, Idkaidek N, Beshtawi M, Bader M, Admour I, Alam SM, Zaman Q, Dham R. Bioequivalence evaluation of two brands of aceclofenac $100 \mathrm{mg}$ tablets (Aceclofar and Bristaflam) in healthy human volunteers. Biopharm Drug Dispos. 2004;25:103-8.

23. Davies NM, McLachlan AJ, Day RO, Williams KM. Clinical pharmacokinetics and pharmacodynamics of celecoxib: a selective cyclo-oxygenase-2 inhibitor. Clin Pharmacokinet. 2000;38:225-42.

24. Paulson SK, Hribar JD, Liu NW, Hajdu E, Bible RH Jr, Piergies A, Karim A. Metabolism and excretion of [(14)C] celecoxib in healthy male volunteers. Drug Metab Dispos. 2000;28:308-14.

25. Turck D, Roth W, Busch U. A review of the clinical pharmacokinetics of meloxicam. Br J Rheumatol. 1996;35 Suppl 1:13-6.

26. Roos EM, Roos HP, Lohmander LS. WOMAC Osteoarthritis Index: additional dimensions for use in subjects with 
42 Moon et al. Efficacy and Safety of Aceclofenac Controlled Release in Knee OA

post-traumatic osteoarthritis of the knee: Western Ontario and MacMaster Universities. Osteoarthritis Cartilage. 1999;7:216-21.

27. Roos EM, Roos HP, Ekdahl C, Lohmander LS. Knee injury and Osteoarthritis Outcome Score (KOOS): validation of a Swedish version. Scand J Med Sci Sports. 1998;8:439-48.

28. Roos EM, Roos HP, Lohmander LS, Ekdahl C, Beynnon BD.
Knee Injury and Osteoarthritis Outcome Score (KOOS): development of a self-administered outcome measure. J Orthop Sports Phys Ther. 1998;28:88-96.

29. Roos EM, Lohmander LS. The Knee injury and Osteoarthritis Outcome Score (KOOS): from joint injury to osteoarthritis. Health Qual Life Outcomes. 2003;1:64. 